\title{
Narrativas da ausência e do poder: o artifício de representação no romance de tese saramaguiano
}

Ramsés Albertoni Barbosa $a^{a}$

Maria Luiza Igino Evaristo ${ }^{b}$

\begin{abstract}
Resumo
No "romance de tese" A caverna, Saramago cria um artifício de representação que permite elucidar formas de domínio, cuja análise parte da crítica ao funcionamento do princípio do mercado que, de um lado, confina o Estado e deslegitima formas de sociabilidade já propostas, seja pela fase liberal, seja pela fase organizada do capitalismo tardio e, de outro, desoculta outras sociabilidades subalternizadas pela modernidade. Enfatiza-se como os discursos éticopolíticos preenchem as condições comunicativas para um autoentendimento hermenêutico de coletividades, porquanto possibilitam uma autocompreensão autêntica e conduzem para a crítica de um projeto de identidade, em que é necessário o preenchimento de certas condições de uma comunicação não-deformada sistematicamente.
\end{abstract}

Palavras-chave: Saramago; capitalismo tardio; sociabilidades; urbanismo; pós-política.

Recebido em: 02/07/2018 Aceito em: 17/11/2018

aProfessor de Literatura e Mestrando em Comunicação (PPGCOM-UFJF). Mestre em Poética (UFRJ). E-mail: ramses.albertoni@ich.ufjf.br.

bProfessora de História e Doutora em Ciência da Religião (PPCIR-UFJF). E-mail: mlieteja@yahoo.com.br. 


\section{Artifícios de representação}

O artigo analisa os "artifícios de representação" (ALTHUSSER, 1968) agenciados no "romance de tese" (SULEIMAN, 1983) A caverna, de Saramago (2000), como uma criação que se relaciona com a representação das identidades urbanas com base nas "afinidades eletivas" (LÖWY, 1989) entre a literatura e as ciências sociais, agenciando a relação dialética que se estabelece entre configurações sociais ou culturais não redutíveis à determinação causal direta ou à influência no sentido tradicional.

A narrativa do romance A caverna (SARAMAGO, 2000) inicia-se quando a louça fabricada manual e artesanalmente pela Olaria Algor é rejeitada pelo Centro Comercial em detrimento das novas tecnologias e das novas técnicas de reprodutibilidade. $\mathrm{O}$ barro é trocado pelo plástico, o original é trocado pela cópia, o artesanal pelo industrial, porquanto instâncias decisórias superiores do Centro, ao perceberem as baixas vendas nas últimas semanas, decidem romper o contrato de exclusividade na compra das louças em razão de, além disso, terem surgido umas louças de plástico que imitavam o barro. Após tal desiderato, o oleiro Cipriano Algor muda os seus hábitos, tornando-se preguiçoso e lento. Durante uma conversa entre pai e filha, Marta Gacho propõe o fabrico de bonecos como proposta alternativa para manterem o funcionamento da olaria. Ao levar a proposta do novo projeto ao Centro, Cipriano é informado sobre a retirada das louças não vendidas do depósito e o cancelamento definitivo e irrevogável do contrato de compra com a Olaria Algor. Posto isso, Cipriano decide mudar-se com a filha e o genro, Marçal Gacho, para o minúsculo apartamento no interior do Centro. Em virtude das obras subterrâneas de ampliação do Centro, algo de extremamente enigmático fora descoberto no subsolo do imenso prédio. Como o genro nada lhe diz a respeito, Cipriano decide investigar o ocorrido e desce até o fundo da gruta aberta pelas escavações,

Com o choque a luz oscilou, diante dos olhos surgiu-lhe, num instante, o que parecia um banco de pedra, e logo, no instante seguinte, alinhados, uns vultos mal definidos apareceram e desapareceram. [...] A luz trémula da lanterna varreu devagar a pedra branca, tocou ao de leve uns panos escuros, subiu, e era um corpo humano sentado o que ali 
estava. Ao lado dele, cobertos com os mesmos panos escuros, mais cinco corpos igualmente sentados, erectos todos como se um espigão de ferro lhes tivesse entrado pelo crânio e os mantivesse atarraxados à pedra. A parede lisa do fundo da gruta estava a dez palmos das órbitas encovadas, onde os globos oculares teriam sido reduzidos a um grão de poeira. [...] este é um homem, esta é uma mulher, outro homem, outra mulher, e outro homem ainda, e outra mulher, três homens e três mulheres, viu restos de ataduras que pareciam ter servido para lhes imobilizar os pescoços, depois abaixou a luz, ataduras iguais prendiam-lhes as pernas. [...] No chão via-se uma grande mancha negra, a terra estava requeimada naquele local, como se durante muito tempo tivesse ardido ali uma fogueira. (SARAMAGO, 2000, p. 331-334)

O pai conta à filha sobre o "mito da caverna" que encontrara no interior do Centro e, ao responder a uma pergunta sobre quem são as três mulheres e os três homens, diz que essas pessoas somos nós, provavelmente a representação do mundo todo. Após o aflitivo prenúncio nas escavações do Centro, as personagens decidem abandonar tudo e procurar outra vida longe do lugar em que residem.

Com base nesse resumo do romance $A$ caverna (SARAMAGO, 2000), é possível compreender a literatura como prática social que expressa, na forma e no conteúdo, o arranjo social, a maneira como a sociedade se organiza, se relaciona, resolve seus conflitos. No âmbito estrito das ciências sociais, pode-se compreender a literatura como um conjunto de textos formalizados e produzidos por uma categoria social determinada, o escritor, preocupada com uma estética da arte e da linguagem que é, conforme Facina (2004), uma síntese da sua época, sujeita aos condicionamentos e orientações das suas múltiplas dimensões de pertencimento, cuja criatividade, em princípio ilimitada, é, de certa forma, balizada por um campo delimitado de possibilidades culturais próprias da sua condição e inserção. Por conseguinte, a realidade social não está diretamente refletida na literatura, uma vez que existem processos mediadores que alteram conteúdos originais, entre uma e outra, por isso, a literatura deve ser apreendida como parte constitutiva da prática social.

As diversas expressões literárias, tanto na sua forma como no seu conteúdo, são, em síntese, expressões de visões de mundo compartilhadas coletivamente e próprias de determinados grupos sociais informados por experiências 
históricas concretas. A literatura, assim como outras concretizações sociais, engendra práticas e representações dos indivíduos e grupos sociais nas quais ela é construída, o que a torna passível e legítima de análise no campo sociológico. Dessa maneira, investigar concepções de mundo e ideias transformadas em textos literários é investigar as condições de sua produção, situando sócio-historicamente autores e temas.

Como expressão do processo cultural, a literatura não pode, portanto, ser compreendida como uma dimensão autônoma da dinâmica social, uma vez que sua existência só tem sentido na relação entre quem escreve e quem lê. Sua natureza é circular nesse intercâmbio, nessa troca constante em algum nível de compartilhamento de universos simbólicos semelhantes. Apesar de serem modos de conhecimento do mundo que renunciam à ideia de que a realidade possa ser apreendida em si, na sua essência, de forma substancializada ou reificada, tanto a literatura quanto as ciências sociais possuem fronteiras intransponíveis, uma vez que o modo de conhecimento literário é impossível de ser reduzido apenas à observação, e seu campo analítico não se limita à procura de leis gerais explicativas do comportamento humano e da organização social, como é, em tese, o objetivo das ciências sociais. Todavia, a lógica literária da pluralidade de personagens, temas e gêneros de escrita supõe e expõe a pluralidade, a diversidade, as singularidades e as especificidades das sociedades. Literatura e ciências sociais não abdicam, assim, da prerrogativa que a realidade social, por conta da sua complexidade, só pode ser conhecida e, principalmente, compreendida com base em um ponto de vista, de uma perspectiva.

Os artifícios de representação, consequentemente, dizem respeito à formulação de Althusser (1968) em que a representação do mundo necessária à coesão social é necessariamente mítica, cuja razão reside no fato de todas as estruturas sociais serem, por definição, opacas para os indivíduos que ocupam postos no seu interior, haja vista que a estrutura formal de toda e qualquer ideologia é uma inversão constante dessa relação real entre as formações sociais e os indivíduos a elas pertencentes, uma vez que o mecanismo-chave de toda e qualquer ideologia é o de construir indivíduos como "sujeitos imaginários" da sociedade, bem como o de garantir a sua sujeição à ordem social, seja como seus pilares cegos, seja como suas vítimas. 
As afinidades eletivas, por outro lado, dizem respeito à reflexão acerca das instâncias de interlocução, aos limites e às possibilidades do diálogo entre duas epistemologias, sendo tomadas, em sentido estrito, como expressão de configurações culturais; ou seja, as afinidades eletivas são o resultado de um arranjo único e de uma inter-relação das partes, o que constitui uma nova entidade que revela as (des)continuidades entre essas duas formas de operacionalização e de compreensão da realidade social. Logo, esse conceito abre possibilidades para a compreensão de realidades e de relações complexas, expandindo o campo para a superação de um reducionismo estrito que apaga nuances dos significados atribuídos às relações sociais estabelecidas. De acordo com Löwy (1989), tanto a produção quanto a recepção e a apropriação dos conceitos são o resultado de uma complexa trama de aproximações e de repulsões, de afinidades e de interditos, de movimentos de convergência, de atração recíproca, de combinação, podendo chegar à fusão em múltiplas escalas e temporalidades. Essa forma, essencialmente antropológica de interpretação e compreensão dos fenômenos da sociedade, expressa no sentido atribuído ao conceito de sociedade, se realiza pela interveniência da mediação, da interação, da fusão, da metamorfose, permitindo, igualmente, justificar processos de interação que não dependem nem da causalidade direta, nem da relação expressiva entre forma e conteúdo, já que não se dá no vazio ou na placidez da espiritualidade pura, sendo (des)favorecida por condições histórico-sociais, cuja análise é compatível com o reconhecimento do papel determinante das condições socioeconômicas.

Na construção do romance de tese (SULEIMAN, 1983) A caverna, Saramago (2000) apropria-se do recurso do formal realism (WATT, 1957), cujo método narrativo incorpora uma visão circunstancial da vida por meio de um conjunto de procedimentos narrativos que são peculiares ao gênero romance, permitindo uma imitação mais imediata da experiência individual situada num contexto temporal e espacial.

O romance em questão é um relato que permanece no núcleo da tensão sem assinalar solução alguma. Saramago (2000) trabalha, de forma estética, a crise contemporânea, refletindo sobre a vida cotidiana sem apontar para qualquer ascese ou transcendência. Sua posição é de crítico da situação atual, pois 
almeja ir além do exterior das situações. Suas personagens sentem uma profunda estranheza com o cotidiano, e a narrativa do romance acompanha essa vida comum a distância, sem se relacionar a um mundo específico, dando-nos, não obstante esse distanciamento, uma percepção aguda dessa mesma realidade. De acordo com Lourenço, Saramago

[...] mergulha a humanidade inteira, abandonada pelo sol da história, numa epidemia de obscurantismo universal de que, por graça humana, só um olhar feminino é promessa de uma redenção, tão paradoxal e misteriosa como a escuridão que num certo instante, como um castigo de Deus inexistente, nos precipita num inferno atapetado de olhos brancos como nos contos de ficção científica. (LOURENÇO, 2001, p. 100-101)

Saramago não retrata um mundo coeso, pois cria, no romance, o molde de apreensão de uma realidade que se esvai em múltiplas versões, cujas regras estão suspensas por uma criação que as violenta em favor de uma observação crítica. Segundo o próprio Saramago,

Creio que, além do meu modesto gosto por contar histórias, o romance, para mim, hoje, é o modo que encontrei para fazer passar umas quantas preocupações, ou, se quiseres, nalguns casos, obsessões minhas. Às vezes, tudo isso me leva a interrogar-me sobre se serei, de facto, um romancista, ou se os meus livros não serão, no fundo, ensaios com personagens. [...] Não é a atitude de quem já sabe o que vai escrever. Sabe que está empenhado em contar uma determinada história. Simplesmente, isso, se calhar, é o menos importante de tudo, o mais importante é o como está a ser contada, e o como está a ser contada depende muito da associação de ideias. (BAPTISTA-BASTOS, 1996, p. 37-40)

É preciso ressaltar, desse modo, que apesar de ser uma convenção, o formal realism possui vantagens específicas, pois existem diferenças importantes no grau em que as diferentes formas literárias mimetizam a realidade, o que lhe permite uma mimesis mais imediata da experiência individual situada num contexto temporal e espacial.

Conforme Lukács (2000), isso vai ocorrer porque a arte se tornou independente dos modelos clássicos; atualmente, o romance já não é mais a cópia de um modelo pré-estabelecido, mas sim uma totalidade criada, visto que a "unidade natural das esferas metafísicas" se rompeu. Portanto, a arte é tão só uma esfera entre muitas que possui, como pressupostos de sua 
existência e conscientização, o esfacelamento e a insuficiência do mundo. O romance, como "epopeia da era burguesa", está, desse modo, paradoxalmente condenado à fragmentariedade e à insuficiência por um substrato histórico-filosófico, além de ser a narrativa de uma era para a qual a totalidade extensiva da vida não se dá de modo evidente, cuja imanência se tornou problemática apesar de possuir uma intenção à totalidade. Como epopeia moderna, o romance dá forma a uma totalidade de vida fechada por meio de si mesma, buscando descobrir e construir, pela forma, a totalidade oculta da vida.

A rigor, o herói da epopeia jamais é um indivíduo, pois seu traço essencial é tratar do destino de uma comunidade, já que a perfeição e a completude do seu sistema de valores articula um todo demasiado orgânico para que uma de suas partes possa tornar-se uma individualidade isolada (LUKÁCS, 2000). A narrativa individual só pode ocorrer sob o peso da vinculação de um destino com uma totalidade, porquanto o destino universal é o que confere conteúdo aos acontecimentos. De acordo com o autor, a perspectiva do narrador, ao contrário, independentemente das convicções particulares de quem escreve, estimula a compreensão da realidade como um processo de transformação incessante, isto é, como um movimento que está permanentemente engendrando o conhecimento.

Segundo Candido (2006), a arte é social em dois sentidos, pois depende da ação de fatores do meio, que se exprimem na obra em graus diversos de sublimação, e produz sobre os indivíduos um efeito prático, modificando a sua conduta e a sua concepção do mundo, ou reforçando neles o sentimento dos valores sociais. Isso decorre da própria natureza da obra e independe do grau de consciência que possam ter a respeito dos artistas, os receptores da arte. Dessa maneira, a primeira tarefa é investigar as influências concretas exercidas pelos fatores socioculturais. É difícil discriminá-los na sua quantidade e variedade, mas pode-se dizer que os mais decisivos se ligam à estrutura social, aos valores e ideologias, às técnicas de comunicação. $\mathrm{O}$ grau e a maneira de influência desses três grupos de fatores variam conforme o aspecto considerado no processo artístico. Assim, os primeiros manifestam-se mais visivelmente na definição da posição social do artista, ou na configuração de grupos receptores; os segundos, na forma e 
no conteúdo da obra; os terceiros, na sua fatura e transmissão. Eles marcam, em todo o caso, os quatro momentos da produção artística, pois o artista orienta-os segundo os padrões da sua época, escolhendo certos temas, usando certas formas, cuja síntese resultante age sobre o meio.

\section{Ponto nodal}

A ficcionalização saramaguiana, no romance A caverna (SARAMAGO, 2000), contrapõe o Centro como um lugar de simulação e de poder articulado à representação de uma cidade invisível, o que impede a construção de identidades num cenário fragmentado e repleto de textos, haja vista que as metrópoles contemporâneas possuem uma complexa arquitetura de territórios que se articulam entre espaços efêmeros-híbridos e espaços identitários, que entrecruzam polaridades fugidias, de lugares e não-lugares, instalando um palimpsesto a embaralhar identidades e relações, pois se o lugar não se apaga completamente, o não-lugar (AUGÉ, 1994) jamais se realiza totalmente.

Ao representar a cidade, a literatura, como discutimos anteriormente, empresta-lhe uma realidade imaginária, ao mesmo tempo que as mudanças urbanas contribuem para transformar o texto literário, uma vez que cada uma dessas instâncias é um reflexo artístico do fenômeno urbano ao qual seus autores assistem, contribui, ela própria, para forjar a imagem desse fenômeno na consciência dos indivíduos. Tratase, assim, de um diálogo que se opera em dois sentidos: a ficção, ao representar a realidade, também contribui para construí-la. Essa intertextualidade entre literatura e espaço social urbano se aguça com o advento da cidade moderna, pois, encarregada de explanar a respeito do mundo contemporâneo, a literatura vê-se diante de um mundo caótico, simbolizado pela grande cidade, que é preciso evidenciar e ao qual se deve dar sentido. Para isso, a literatura precisa mergulhar fundo nos contrastes, na confusão e na miséria da cidade contemporânea, de modo a cumprir o seu papel de mediadora de uma experiência social urbana estranha e desordenada. Esse mergulho nas entranhas da cidade contemporânea exige da literatura um despojamento em relação a alguns dos seus princípios que a definiam anteriormente. É preciso, em primeiro lugar, levar 
em conta o esfacelamento de uma ordem social, cujos papéis desempenhados por cada indivíduo eram pré-definidos; é preciso dar conta, além disso, de uma espantosa dispersão geográfica; e, por fim, é inevitável abrir os olhos para uma realidade muitas vezes dramática.

A relação entre a personagem Cipriano e o Centro é o ponto nodal a partir do qual Saramago (2000) constrói sua crítica ao capitalismo, que se coaduna com a análise mais específica de teóricos da cultura. De acordo com Marx (1996), a burguesia só poderia existir com o aperfeiçoamento constante dos instrumentos de produção e, por conseguinte, com a mudança das relações de produção e de todas as relações da sociedade. Segundo Santos (1997), a alienação e a reificação do capitalismo fazem parte dos quatro axiomas fundamentais da modernidade que formam a base dos problemas atuais, quais sejam: a hegemonia que a racionalidade científica veio a assumir e consiste na transformação dos problemas éticos e políticos em problemas técnicos; a legitimidade da propriedade privada, independentemente da legitimidade do uso da propriedade; a soberania dos Estados e da obrigação política vertical dos cidadãos perante esses Estados; a crença no progresso entendido como um desenvolvimento infinito, alimentado pelo crescimento econômico, pela ampliação das relações e pelo desenvolvimento tecnológico.

A ampla guinada na análise das questões mais prementes da contemporaneidade, descritas no romance A caverna (SARAMAGO, 2000), será articulada por Jameson (1996), que desenvolve o termo "capitalismo tardio", cunhado por Mandel, com base num conceito que funciona como uma espécie de signo carregado de intenções e consequências, pois o capitalismo é hoje menos um modo de produção que um modo de vida. Mandel (1982) aborda a emergência da "racionalidade tecnológica" como ideologia dominante, que é a primeira teoria da história do capital, surgida no pós-guerra, que fornece a base empírica e conceitual de compreensão do presente numa configuração renovadora desse modo de produção. Conforme Mandel (1982), o capitalismo tardio não é uma mera mudança do capitalismo, mas uma subfase da época imperialista, cuja concepção possui duas características essenciais: a primeira é a tendência em aumentar a rede de controle burocrático em suas formas mais assustadoras; a segunda é a interpenetração 
entre governo e big business, semelhante ao que ocorreu com o nazismo. $\mathrm{O}$ que caracteriza atualmente esse conceito é um sistema capitalista mundial que persiste nos procedimentos do antigo imperialismo.

No capitalismo tardio agencia-se o dispositivo complexo ternário da mundialização das trocas, da universalidade dos valores, das singularidades das formas. Tal sistema sinaliza a universalização do particular de alguém que é imposto a todo mundo; assim, as diferenças e os antagonismos desaparecem em razão do desenvolvimento do mercado mundial e da uniformidade no modo de produção. O mundo hodierno transformou-se num lugar onde só existe o dentro que anula o fora, não havendo dialética possível, pois quem está dentro do sistema tem existência, mesmo que sub-reptícia, e quem está fora não existe, como se pode perceber na citação seguinte:

O oleiro parou a furgoneta, desceu os vidros de um lado e do outro, e esperou que alguém aparecesse para o roubar. Não é raro suceder que certas desesperações de espírito, certos encontrões da vida empurrem a vítima a decisões tão dramáticas como esta, quando não piores. Chega um momento em que a pessoa transtornada ou injuriada ouve uma voz a gritar dentro da sua cabeça, Perdido por dez, perdido por cem, e então é consoante as particularidades da situação em que se encontre e o lugar onde ela o encontrou, ou gasta o último dinheiro que lhe restava num bilhete de lotaria, ou atira para a mesa de jogo o relógio que havia herdado do pai e a cigarreira de prata que a mãe lhe deu, ou aposta quanto tem no vermelho apesar de ter visto que a cor saiu cinco vezes seguidas, ou sobe sozinho da trincheira e corre de baioneta calada contra a metralhadora do inimigo, ou pára esta furgoneta, desce os vidros, abre depois as portas, e põe-se à espera de que, com os porretes do costume, as navalhas de sempre e as necessidades da ocasião, o venha saquear a gente das barracas, Se não o quiseram aqueles, então que o levem estes, foi o último pensamento de Cipriano Algor. (SARAMAGO, 2000, p. 25)

Se, de um lado, existe a opulência do Centro e o consumismo exagerado e frívolo, por outro lado, existe um lugar bem próximo, assustador, com aglomerações caóticas de barracas precárias que não defendem das intempéries os seus moradores desamparados, os quais continuamente assaltam caminhões carregados de alimentos, uma vez que apenas os "vencedores" estão participando dos efeitos positivos da economia global. 


\section{Comunicatividades}

A "comunidade da mesmidade" (BAUMAN, 2004) em que vive o oleiro e sua família apoia-se primordialmente na atividade artesanal, cujo tempo é diferente do tempo da atividade industrial, que possui um caráter fragmentário e totalizante. O trabalho artesanal está inserido num tempo mais global que permite a narrativa de um saber, de uma prática, de um conselho. $\mathrm{O}$ narrador artesanal é sempre fiel à sua época e jamais esquece as criaturas que vê passar em cortejo diante de seus olhos. A residência e a olaria da família Algor foram construídas num amplo terreiro no centro do qual o pai de Cipriano, também oleiro, decidiu plantar uma amoreira. Durante uma conversa com a sua filha Marta, Cipriano se questiona sobre a continuidade do ofício familiar de oleiros:

[...] Não quererás continuar a trabalhar de oleira para o resto da tua vida, Não, embora goste do que faço, Deves acompanhar o teu marido, amanhã terás filhos, três gerações a comer barro é mais do que suficiente, E o pai está de acordo em ir connosco para o Centro, deixar a olaria, perguntou Marta, Deixar isto, nunca, está fora de questão, Quer dizer que passará a fazer tudo sozinho, [...] recordo-lhe que as coisas já vão sendo bastante difíceis apesar da ajuda que nos dá Marçal no pouco tempo que cá está, Hei-de encontrar quem me auxilie, não faltam rapazes na povoação, Sabe perfeitamente que já ninguém quer ser oleiro, aqueles que se fartam do campo vão para as fábricas da Cintura, não deixam a terra para vir para o barro, Mais uma razão para que largues isso. (SARAMAGO, 2000, p. 31)

Fica-nos claro que a família que constrói a sua existência em torno da velha Olaria Algor é um grupo que almeja erigir uma transcendência, porquanto se pauta por procedimentos de uma comunidade da mesmidade; todavia, é preciso convir que os seus integrantes estão inseridos numa cultura consumista que favorece o ready-made na sua imediatez, cujos prazeres voláteis e satisfações imediatas não exigem esforços e comprometimentos prolongados. De um lado, a compulsão por consumo; de outro, a construção do amor, a vontade de cuidar, de preservar o objeto cuidado. Um dos traços da "modernidade líquida", de que trata o romance de Saramago (2000), diz respeito ao problema da insegurança prefigurada pela fragilidade dos laços humanos, pois, se o desejo quer consumir, o amor quer possuir (BAUMAN, 2003). 
De um lado, temos o "desejo shopping", a satisfação instantânea; de outro, as personagens do romance $A$ caverna (SARAMAGO, 2000), que possuem uma matéria sólida a ser preenchida e revelada. Ressalte-se que, na modernidade líquida, se instaura a "comunidade de ocasião", autoconstruída em torno do efêmero dos eventos, cujas "relações de bolso" são doces e instantâneas. Duas são as condições para que se apresente esse tipo de relação em uma "comunidade imaginada", cuja autoidentificação vai dar-se com uma dilatada categoria de desconhecidos com quem se crê partilhar algo pertinente. A primeira condição é a de se embarcar no relacionamento plenamente cônscio e totalmente sóbrio, pois a conveniência é a alma do negócio. A segunda condição é a de se manter do jeito que se é, pois não se deve perder o controle das "subcorrentes emocionais". Deve-se sempre lembrar que o prazer é sustentado pelo tráfego constante, o bolso deve estar sempre livre e preparado para os próximos encontros. A arte de romper os relacionamentos e sair quase ileso é bem diferente da arte de constituir relacionamentos. Os compromissos familiares e trabalhistas duradouros, como os desempenhados pelas personagens do romance de Saramago (2000), são entrevistos como opressivos e incapacitantes pela modernidade líquida, pois tornam impuras as relações humanas que devem se balizar pelos atos de consumo, pela satisfação instantânea e pela obsolescência do objeto consumido. Conforme Bauman (2004), os alvos principais do ataque do mercado são os seres humanos como produtores,

Numa terra totalmente conquistada e colonizada, somente consumidores humanos poderiam obter permissão de residência. A difusa indústria familiar das condições de vida compartilhadas seria posta fora de operação e desmantelada. As formas de vida, e as parcerias que as sustentam, só estariam disponíveis como mercadorias. O estado obcecado com a ordem combateu (correndo riscos) a anarquia, aquela marca registrada da communitas, em função da ameaça à rotina imposta pelo poder. O mercado consumidor obcecado pelos lucros combate essa anarquia devido à turbulenta capacidade produtiva que ela apresenta, assim como o potencial para a autossuficiência que, ao que se suspeita, crescerá a partir dela. É porque a economia moral tem pouca necessidade do mercado que a força deste se levanta contra ela. (BAUMAN, 2004, p. 24-25) 
Essa é uma estratégia de mão dupla, pois se, de um lado, mercantiliza-se e remodela-se, sob a forma do consumo, o maior número de aspectos da economia moral, de outro, nega-se qualquer relevância para a prosperidade da sociedade de aspectos dessa mesma economia moral que resista à mercantilização. Dessa forma, a modernidade líquida atinge todos os setores da vida social numa inédita fluidez, fragilidade e transitoriedade em construção que marca todas as espécies de vínculos sociais.

Ao retomar o mito platônico da caverna e atualizá-lo no universo do Centro, Saramago (2000) põe em questão a tentativa de se descartar as concepções humanas desenvolvidas ao longo da história. Em contraponto ao obsoletismo da sociedade do efêmero, o autor defronta-nos com a percepção de outra época e outra sociedade com o intuito de nos mostrar que o que é verdadeiramente humano é sempre o mesmo, apesar das mudanças ao longo dos tempos, pois o que nos é essencial é duradouro e indispensável.

Portanto, este artigo procura enfatizar como os discursos ético-políticos preenchem as condições comunicativas habermasianas para um autoentendimento hermenêutico de coletividades, porquanto devem possibilitar uma autocompreensão autêntica e conduzir para a crítica de um projeto de identidade em que é necessário o preenchimento de certas condições de uma comunicação não-deformada sistematicamente e que proteja os participantes contra repressões, sem arrancá-los de seus genuínos contextos de experiências e interesses.

A análise social abrangente de Habermas (1999) vinculase ao conceito de "fato social total" de Mauss (2010), ou seja, é um sistema de conhecimento que articula o simples e o complexo, uma vez que, na formulação maussiana, está pressuposta a presença de sistemas de reciprocidades das atividades humanas que se sustentam por um simbolismo generalizado em todos os planos da vida, estendendo-se do plano do cotidiano às estruturas formais da economia, da política, da religião, da ciência, entre outros. Desse modo, o conceito de "razão comunicativa", de Habermas (1999), deriva da relação comunicativa entre as pessoas e pode produzir entendimento nos processos de socialização, agenciados por meio da relação entre trabalho e interação social que, além 
de gerarem produção técnica e informação, permitem, pela linguagem, que se interpretem os acontecimentos, orientando a ação e desmascarando as relações de dominação.

Existem dois tipos de ação, segundo o autor, a não social, guiada por regras técnicas para intervir eficazmente no mundo, chamada de ação instrumental; e a ação social, dividida em dois subtipos: ação estratégica (guiada por regras racionais que implicam decisão) e ação comunicativa (visa ao entendimento e ao consenso, os atores compartilham a definição de uma situação) (HABERMAS, 1999). No conceito harbemasiano de contexto comunicativo, interagem três fatores, quais sejam, a comunicação, a emancipação e a identidade do eu, articulados em termos de reciprocidade e de consenso. Habermas (1999) coloca como ponto primordial de sua teoria o paradigma da comunicação intersubjetiva da ação comunicativa que se contrapõe à ação estratégica, constituindo um novo tipo de racionalidade comunicativa que demanda uma teoria da sociedade em que o "sistema" coloniza o "mundo da vida". Conforme o autor, o conceito de racionalidade comunicativa difere da racionalidade instrumental e cognitiva, pois se sustenta num conceito de sociedade que engloba dois paradigmas, o de mundo da vida e o de sistema, além de delinear uma teoria da modernidade que dá conta das novas patologias sociais como decorrência da submissão da ação comunicativa aos imperativos do sistema, pois se trata da racionalidade encarnada em saberes falíveis que dizem respeito ao mundo objetivo, acerca do qual é possível fazer juízos objetivos, pautados por uma pretensão intersubjetiva de validez.

Ousocomunicativo de recorte habermasiano problematiza, dessa maneira, o mundo em função da necessidade de reconhecer as situações em sua objetividade, tendo em vista o entendimento entre sujeitos capazes de linguagem e de ação, cuja prática comunicativa cotidiana se dá no contexto do mundo da vida que, compartilhado intersubjetivamente na totalidade das interpretações pressupostas, é um saber de fundo. Com apoio em teorias sociológicas baseadas na ação comunicativa, Habermas (1999) considera que só o conceito de ação comunicativa pressupõe a linguagem como um meio de entendimento. Portanto, todas as funções da linguagem são levadas em conta, pois não é mera conversação, mas coordena a ação e ajusta os planos respectivos dos participantes 
na comunicação a fim de que possam interagir. A ação comunicativa visa ao entendimento entre pessoas competentes para agir e falar. O conteúdo proposicional do ato de fala é objeto de discussão, as pessoas levam em conta informações, convicções, aceitam ou não a oferta do ato de fala e posicionamse de acordo com um princípio de validez suscetível de revisão e crítica. Não obstante isso, se o entendimento é imanente à linguagem, deve-se ressaltar que existem obstáculos e limites a esse processo de integração pela comunicação, como a preponderância da racionalização instrumental e a tendência do "sistema" prejudicar a socialização comunicativa, porquanto perfaz a colonização do "mundo da vida". Consequentemente, Habermas (1999) desenvolve o conceito "mundo da vida" como um lugar em que se dá a integração social, contrapondo-se ao "sistema" que produz apenas integração sistêmica. A concepção de sociedade como mundo da vida resulta da perspectiva conceptual da ação orientada para o entendimento; por conseguinte, o autor propõe que se entenda a sociedade por um conceito dual, como sistema e como mundo da vida, que distingue entre a racionalização do mundo da vida e o aumento da complexidade dos sistemas sociais.

Esse entendimento deve ser compreendido como o overlapping consensus proposto por Rawls (2000), ou seja, uma concepção política de justiça que governa as instituições básicas da sociedade, sendo o objeto em torno do qual se estabelece um consenso que estabeleça uma unidade social adaptada à sociedade. Dessa maneira, para que o overlapping consensus de recorte rawlsiano (RAWLS, 2000) seja construído de forma satisfatória, é mister agir comunicativamente, no lugar transcendental do mundo da vida, por meio de atos de fala que objetivam algo no mundo e que são usados para normatizar a esfera do mundo social, expressando algo do mundo subjetivo, em que falante e ouvinte vão um ao encontro do outro e pretendem que suas emissões estejam de acordo com o mundo, criticando e mostrando os fundamentos de suas pretensões de validez, resolvendo seus desentendimentos, até chegar a um acordo. As estruturas gerais que se erguem no mundo da vida são a cultura que reproduz e dá coerência ao saber necessário para a prática comunicativa; a sociedade que integra a ação num tempo histórico, coordenando-a por relações legítimas; e a personalidade que é socializada a ponto 
de chegar a ações autônomas. O mundo da vida é formado, assim, por convicções e modelos de interpretação (morais, éticos, práticos) que funcionam como uma rocha, contra a qual batem a experiência e a crítica (KRITSCH; SILVA, 2011).

Posto isso, é preciso ressaltar que a racionalidade técnica incorporada pelo Centro do romance $A$ caverna (SARAMAGO, 2000) é a racionalidade da própria dominação, da colonização do mundo da vida pelo sistema econômico, em que nada deve ser produzido e comercializado sem corresponder às tabelas do consumidor padrão, do público-alvo, pois, em seu lazer, as pessoas devem se orientar por essa unidade que caracteriza a produção, não havendo nada mais a classificar que não tenha sido antecipado em tal esquematismo. Nesse universo, o sensível é substituído por imagens que se fazem reconhecer como o sensível por excelência e, no interior do Centro, encontra-se um mundo, como ilustra o seguinte fragmento do romance:

[...] os andares, as galerias, as lojas, as escadarias de aparato, as escadas rolantes, os pontos de encontro, os cafés, os restaurantes, os terraços com mesas e cadeiras, os cinemas e os teatros, as discotecas, uns ecrãs enormes de televisão, infinitas decorações, os jogos electrónicos, os balões, os repuxos e outros efeitos de água, as plataformas, os jardins suspensos, os cartazes, as bandeirolas, os painéis publicitários, os manequins, os gabinetes de provas, uma fachada de igreja, a entrada para a praia, um bingo, um casino, um campo de ténis, um ginásio, uma montanha-russa, um zoológico, uma pista de automóveis eléctricos, um ciclorama, uma cascata, tudo à espera, tudo em silêncio, e mais lojas, e mais galerias, e mais manequins, e mais jardins suspensos, e coisas de que provavelmente ninguém conhece os nomes, como uma ascensão ao paraíso. (SARAMAGO, 2000, p. 277)

Atualmente, uma mercadoria precisa conquistar o consumidor para ser comprada por fatores além da razão, tais como mistério, intimidade e sensualidade. Durante uma conversa com o subchefe do Centro, Cipriano escuta o funcionário lhe dizer que não irá revelar-lhe o "segredo da abelha":

Sempre ouvi que o segredo da abelha não existe, que é uma mistificação, um falso mistério, uma fábula que ficou por inventar, um conto que podia ter sido e não foi, Tem razão, o segredo da abelha não existe, mas nós conhecemolo. Cipriano Algor retraiu-se como se tivesse sido vítima de uma agressão inesperada. [...] Vira cair uma máscara e 
percebera que por trás dela estava outra exactamente igual, compreendia que as máscaras seguintes seriam fatalmente idênticas às que tivessem caído, é verdade que o segredo da abelha não existe, mas eles conhecem-no. Não poderá falar desta sua perturbação a Marta e a Marçal porque eles não entenderiam, e não entenderiam porque não tinham estado ali com ele, do lado de fora do balcão, a ouvir um subchefe de departamento explicar o que é valor de troca e valor de uso, possivelmente o segredo da abelha reside em criar e impulsionar no cliente estímulos e sugestões suficientes para que os valores de uso se elevem progressivamente na sua estimação, passo a que se seguirá em pouco tempo a subida dos valores de troca, imposta pela argúcia do produtor a um comprador a quem foram sendo retiradas pouco a pouco, subtilmente, as defesas interiores resultantes da consciência da sua própria personalidade, aquelas que antes, se alguma vez existiu um antes intacto, lhe proporcionaram, embora precariamente, uma certa possibilidade de resistência e autodomínio. (SARAMAGO, 2000, p. 239-240)

O segredo da abelha revela-se, no universo do capitalismo tardio, como uma novidade para o consumidor, pois a revolução tecnológica está tão entranhada em sua consciência que a novidade se tornou o principal recurso de vendas, pois se crê que o novo equivale ao categoricamente revolucionado, uma vez que, se a economia transforma o mundo, ela o transforma simplesmente como o mundo da economia que perfaz a exibição incessante do poder econômico sob a forma da mercadoria espetacular que foi levada a uma espantosa inversão do seu tipo de justificativa enganosa (DEBORD, 1971). Desse modo, o consumidor real torna-se um mero consumidor de ilusões. O recurso principal dessa sociedade do espetáculo é a propaganda universal de si mesma como pura representação do poderio social (ADORNO, 1995). A paisagem urbana e a do Centro tornaram-se um mero pano de fundo para a publicidade como arte pura. Percebemos isso quando, em dado momento, a personagem Cipriano comenta com o genro e com a filha que passou um dia inteiro a copiar frases espalhadas pelo interior do Centro:

Então Cipriano Algor tirou do bolso um papel, Copiei estas frases de alguns cartazes expostos, disse, espero não ter chamado a atenção de nenhum espia ou observador, Também o espero, disse Marçal de mau humor, É suspeito copiar frases que estão expostas para os clientes lerem, perguntou Cipriano Algor, Lê-las é normal, copiá-las não, e tudo o que não seja normal é, pelo menos, suspeito de anormalidade. 
Marta, que até aí não tinha participado na conversa, pediu ao pai, Leia lá as frases. Cipriano Algor alisou o papel em cima da mesa e começou a ler, Seja ousado, sonhe. Olhou para a filha e para o genro, e como eles não pareciam dispostos a comentar, continuou, Viva a ousadia de sonhar, esta é uma variante da primeira, e agora vêm as outras, uma, ganhe operacionalidade, duas, sem sair de casa os mares do sul ao seu alcance, três, esta não é sua última oportunidade mas é a melhor, quatro, pensamos todo o tempo em si é a sua altura de pensar em nós, cinco, traga os seus amigos desde que comprem, seis, connosco você nunca quererá outra coisa, sete, você é o nosso melhor cliente mas não o diga ao seu vizinho, Essa esteve lá fora, na fachada, disse Marçal, Agora está dentro, os clientes devem ter gostado, respondeu o sogro. (SARAMAGO, 2000, p. 312)

O Centro recorrerá também ao uso de enormes cartazes, exibidos em sua fachada, com dizeres sobre segurança, necessidade, amizade, entretenimento, cordialidade. $\mathrm{O}$ primeiro cartaz diz: VIVA EM SEGURANÇA, VIVA NO CENTRO, PEÇA INFORMAÇÕES; o segundo diz: VENDERLHE-ÍAMOS TUDO QUANTO VOCÊ NESSECITASSE SE NÃO PREFERÍSSEMOS QUE VOCÊ PRECISASSE DO QUE TEMOS PARA VENDER-LHE. No final do romance, ao resolverem partir e abandonar o mundo sufocante criado pelo Centro, Marta e Marçal leem o último e profético cartaz exibido: BREVEMENTE, ABERTURA AO PÚBLICO DA CAVERNA DE PLATÃO, ATRACÇÃO EXCLUSIVA, ÚNICA NO MUNDO, COMPRE JÁ A SUA ENTRADA.

O recurso da mensagem publicitária empregado pelo Centro agencia procedimentos publicitários para persuadir as pessoas a fazerem o que se deseja que façam, pois o inconsciente deseja sonhar, em plenitude, com algo de positivo, por isso, uma mensagem publicitária negativa jamais será persuasiva. O Centro filtra forçosamente o mundo inteiro, produzindo produtos que serão consumidos de forma voraz. Modelados violentamente por uma organização tecnológica, os cidadãos reproduzem-se na imitação da cópia. Na mônadaCentro do romance, o mínimo de exterioridade é excluído no desejo dominador de expressar o mundo inteiro, na tendência a fazer-se igual a Deus para onde todos os caminhos confluem. O Centro acabou por gerar de si mesmo e em si mesmo, por pura necessidade, algo que pode chocar certos ortodoxos mais sensíveis, ou seja, uma natureza divina. Ou quem sabe, num 
discurso médico, o Centro se assemelha àquela aberração da fisiologia humana que a medicina conhece como o estômago que se digere a si mesmo.

\section{A cidade ausente}

As considerações a respeito da forma narrativa do romance, do capitalismo tardio e da ação comunicativa permitem avançar no que tange às questões da representação da cidade invisível e transparente de Saramago (2000), pois a leitura marxiana das cidades considera que elas são consequência da divisão social do trabalho e do desenvolvimento das forças produtivas.

É no trajeto percorrido por Cipriano e Marçal, entre a Olaria Algor e o Centro, que podemos vislumbrar a extrema visibilidade do Centro e a extrema invisibilidade da cidade:

Entre as barracas e os primeiros prédios da cidade, como uma terra-de-ninguém separando duas facções enfrentadas, há um largo espaço despejado de construções, porém, olhando com um pouco mais de atenção, percebe-se no solo uma rede entrecruzada de rastos de tractores, certos alisamentos que só podem ter sido causados por grandes pás mecânicas, essas implacáveis lâminas curvas que, sem dó nem piedade, levam tudo por diante, a casa antiga, a raiz nova, o muro que amparava, o lugar de uma sombra que nunca mais voltará a estar. [...] Já estavam na periferia da cidade, haveria ainda que percorrer umas quantas ruas de traçado confuso, virar à esquerda, virar à direita, outra vez à esquerda, outra vez à direita, agora à direita, à direita, esquerda, esquerda, direita, em frente, finalmente desemborcariam numa praça a partir da qual se acabavam as dificuldades, uma avenida em linha recta levava-os aos seus destinos, ali onde era esperado o guarda interno Marçal Gacho, alem onde deixaria a sua carga o oleiro Cipriano Algor. Ao fundo, um muro altíssimo, escuro, muito mais alto que o mais alto dos prédios que ladeavam a avenida, cortava abruptamente o caminho. Na realidade, não o cortava, supôlo era o efeito de uma ilusão de óptica, havia ruas que, para um lado e para o outro, prosseguiam ao longo do muro, o qual, por sua vez, muro não era, mas sim a parede de uma construção enorme, um edifício gigantesco, quadrangular, sem janelas na fachada lisa, igual em toda a sua extensão. (SARAMAGO, 2000, p. 16-17)

A cidade invisível do romance A caverna (SARAMAGO, 2000) representa um lugar de ausência, enquanto o Centro representa um lugar de simulação. No universo das 
virtualidades em que é possível tornar real uma situação hipotética com a manipulação de imagens, o que mais inquieta é a passividade com que se aceita o absurdo urbano que, deformado, corrompe as mentalidades indiferentes pelo espaço público, agredido por mutações incontroláveis. Não é à toa que Saramago (2000) vai articular, em seu romance, um contraponto entre o Centro e a cidade.

O termo cidade (do latim civitate) significa o complexo demográfico formado, social e economicamente, por uma importante concentração populacional, não agrícola, dedicada a atividades de caráter mercantil, industrial, financeiro e cultural. É a urbe, a expressão palpável da necessidade humana de contato, comunicação, organização e troca, numa determinada circunstância físico-social e num contexto histórico. A leitura marxiana das cidades considera que elas são a consequência da divisão social do trabalho e do desenvolvimento das forças produtivas. A morte do campesinato foi a mudança social mais impressionante e de mais longo alcance do século XX, confirmando-se a previsão de Marx (1996) de que a industrialização eliminaria o campesinato. $\mathrm{O}$ autor caracteriza a cidade industrial como um mercado não só de capitais, mas também de mão-de-obra, na medida em que ela abarca a população diretamente necessária ao processo produtivo e o exército industrial de reserva, requerido para comprimir os salários bem como para se dispor de um reservatório de trabalhadores. Desse modo, a cidade tem uma importância decisiva na acumulação de capital, já que a presença de um mercado é uma exigência para a realização da mais-valia, que é diretamente proporcional à amplitude desse mercado.

Deve-se a Jameson (1986) e a Lefebvre (2001) a noção da predominância do espaço na contemporaneidade, os quais consideram a importância histórica dos vários modos de produção, cujos tempos e espaços são vivenciados distintamente. As cidades são, igualmente, o contexto no qual se desenrola a luta de classes e a formação de uma consciência revolucionária. Lefebvre (1999) reconhece e enfatiza o valor do urbano e da nova globalidade do sistema na experiência contemporânea, pois os modos de produção constituem modos distintos da produção do espaço.

É preciso destacar que a noção de lugar na cidade contemporânea tem como contraponto a noção de "não-lugar" 
(AUGÈ, 1994), ou seja, um espaço descontínuo de identificação do sujeito em permanente deslocamento que desterritorializa a experiência individual, instituindo a possibilidade do voltar-se sobre si mesmo na abertura de reconfigurações da subjetividade. Conforme Choay (1992), o urbanismo, como "apanágio de especialistas", surge com a "despolitização do pensamento relativo ao planejamento urbano", cujo interesse se transfere das estruturas socioeconômicas para as estruturas técnico-estéticas, tornando-se o urbanista um especialista disponível para a nova classe dirigente. Não obstante, de acordo com Martins (2000), o urbanismo corresponde a um saber político que articula uma práxis que contém múltiplos elementos sociológicos. A realidade desigual das nossas cidades é consequência de complexos processos históricos de conformação e consolidação da hegemonia política e econômica das classes dominantes, por meio da constante e predadora exploração do trabalho assalariado, em uma promíscua aliança com o Estado e sua estrutura burocrática, patrimonialista e clientelista (BURNETT, 2009).

A cidade do romance A caverna (SARAMAGO, 2009), ressalve-se, é um fantasma onipresente, apenas vislumbrado em toda a leitura, uma vez que não possui um corpo sólido como os corpos das personagens Cipriano, Marta, Marçal e, sobretudo, do Centro; contudo, sua presença incomoda, pois fala de algo olvidado e essencial, apesar de sua ausência e de seu silêncio quase absoluto. É no trajeto percorrido por Cipriano e Marçal, entre a Olaria Algor e o Centro, que se pode entrever a cidade:

[Cipriano] Fez virar a furgoneta para uma rua paralela reservada à circulação local, Vamos atalhar caminho por aqui, disse, se a polícia nos perguntar por que saímos da estrada, recorda-te da combinação, temos um assunto a tratar numa destas fábricas antes de chegarmos à cidade. [...] Depois da Cintura Industrial principia a cidade, enfim, não a cidade propriamente dita, essa avista-se lá adiante, tocada como uma carícia pela primeira e rosada luz do sol, o que aqui se vê são aglomerações caóticas de barracas feitas de quantos materiais, na sua maioria precários, pudessem ajudar a defender das intempéries, sobretudo da chuva e do frio, os seus mal abrigados moradores. [...] Não tardará muito que os edifícios da cidade avancem em linha de atiradores e venham assenhorear-se do terreno, deixando entre os mais adiantados deles e as primeiras barracas apenas uma 
faixa estreita, uma nova terra-de-ninguém, que assim ficará enquanto não chegar a altura de se passar à terceira fase. (SARAMAGO, 2000, p. 13-16)

Saramago pontua, em seu romance, que, ao perder a esperança de encontrar, no ambiente urbano, o cumprimento de seus objetivos sociais, o indivíduo moderno encontra-se sozinho com o seu contrário na ausência da cidade de vidro estruturada pelos espaços vazios do não-lugar, uma categoria que não tem relacionamentos, identidade e história, e que realiza um esvaziamento sistemático da consciência. Logo, o não-lugar (AUGÉ, 1994) é um lugar de propriedade negativa, uma espécie de "lugar ausente de si mesmo" que perpetra a socialização na solidão.

A análise da estrutura textual do romance é considerada, desse modo, como sendo mediatizada por estruturas sociais e/ou econômicas heterônomas, pois a sociedade e as suas transformações históricas são interpretadas, no texto, tendo como base as relações sociológicas. Se o mundo moderno é, por um lado, o mundo da revolução tecnológica e da liquidação das formas tradicionais da cultura, é, além disso, por outro lado, o mundo do desencontro fatal entre esse desenvolvimento da técnica e uma ordem social que não se renova.

Marçal tenta explicar a Cipriano o que é o Centro, contudo, o sogro é mais perspicaz em sua avaliação:

[...] a melhor explicação do Centro ainda seria considerá-lo como uma cidade dentro de outra cidade, Não sei se será a melhor explicação, de qualquer modo não é suficiente para que eu perceba o que há dentro do Centro, $\mathrm{O}$ que há é o mesmo que se encontra numa cidade qualquer, lojas, pessoas que passam, que compram, que conversam, que comem, que se distraem, que trabalham, Queres tu dizer, exactamente como na aldeola atrasada em que vivemos, Mais ou menos, no fundo trata-se de uma questão de tamanho, A verdade não pode ser tão simples, Suponho que há algumas verdades simples, É possível, mas não acredito que as possamos reconhecer dentro do Centro. Houve uma pausa, depois Cipriano Algor disse, E já que estamos a falar de tamanhos, é curioso que de cada vez que olho cá de fora para o Centro tenho a impressão de que ele é maior do que a própria cidade, isto é, o Centro está dentro da cidade, mas é maior do que a cidade, sendo uma parte é maior que o todo, provavelmente será porque é mais alto que os prédios que o cercam, mais alto que qualquer prédio da cidade, provavelmente porque desde o princípio tem estado a engolir ruas, praças, quarteirões 
inteiros. Marçal não respondeu logo, o sogro tinha acabado de dar expressão quase visual à confusa sensação de perdimento que se apoderava dele de cada vez que regressava ao Centro depois da folga, sobretudo durante as rondas nocturnas com a iluminação reduzida, percorrendo as galerias desertas, descendo e subindo nos elevadores, como se vigiasse o nada para que continuasse a ser nada. No interior de uma grande catedral vazia, se levantarmos os olhos para as abóbadas, para as obras superiores, temos a impressão de que ela é mais alta do que a altura a que vemos o céu num campo aberto. (SARAMAGO, 2000, p. 258-259)

O Centro, dessa forma, extingue a cidade como lugar antropológico da cultura, como expressão palpável da necessidade humana de contato, comunicação, organização e troca, numa determinada circunstância físico-social e num contexto histórico, além de ser consequência da divisão social do trabalho e do desenvolvimento das forças produtivas. A cidade do romance saramaguiano é um mero lugar de passagem e de trânsito, já que todos vivem, e desejam viver, encarcerados em lugares de segurança absoluta, domínio, controle e previsibilidade como o Centro. Estamos no meão da dialética entre a extrema visibilidade do Centro, com sua insistente luz artificial, e a extrema invisibilidade da cidade.

A Carta de Atenas (LE CORBUSIER, 1993) fixou que as quatro funções básicas da cidade são habitação, trabalho, lazer e circulação. Contudo, novas funções para a cidade vão se somando, algumas dessas funções já existiam na cidade antiga, porém não possuíam a importância que hoje se dá a elas, por diversos fatores que vieram a se agregar a essa nova/velha cidade. A nova Carta de Atenas, elaborada pelos arquitetos europeus, é a cidade conectada, instantânea, que utiliza as novas tecnologias de informação. E essa conexão também deveria ocorrer no campo social, por meio de um compromisso de equilíbrio da sua diversidade e riqueza multicultural, seja no âmbito econômico, seja no do meio ambiente e do planejamento urbano. Os conceitos e funções da cidade do século XXI são divididos em três grupos: funções urbanísticas (habitação, trabalho, lazer e mobilidade), funções de cidadania (educação, saúde e segurança) e as funções de gestão (prestação de serviços, planejamento e preservação do patrimônio cultural e natural). 
Não obstante, de acordo com Rancière (1995), o fim da alternativa socialista não significou qualquer renovação do debate democrático, mas sim a redução da vida democrática para a gestão das consequências locais de necessidade econômica global que impôs as mesmas soluções consensuais a todos como o supremo valor democrático. Com relação às cidades, entendidas como um fenômeno urbano, essa mudança significou, conforme Swyngedouw (2007), aceitar as implicações do deslocamento socioeconômico urdido pela reorganização da produção e da demanda em escala global, pela rede transnacional de empresas e indivíduos, pelos fluxos de investimento especulativo global e pela reestruturação rápida dos mercados de trabalho. Por conseguinte, redefiniu-se a agenda urbana que reflete um foco político que se distancia das considerações reguladoras e distributivas em razão da promoção do crescimento econômico e da competitividade. $\mathrm{O}$ surgimento dessa nova modalidade de governança urbana se enquadra, conforme Arantes (2000), numa linguagem comum e consensual de criatividade competitiva, flexibilidade, eficiência, empreendedorismo estatal, parcerias estratégicas e vantagens colaborativas. O pensamento tecnoadministrativo consensual é a negação da base democrática para a política, pois visa possuir grupos bem identificáveis com interesses, aspirações, valores e cultura específicos. A ocorrência de um deslocamento de técnicas de governança formais para técnicas informais e o aparecimento de novos atores na cena urbana, instituíram uma reorganização tríplice que procura organizar a "conduta da conduta", combinando um desejo de, politicamente, construir o mercado como a instituição social preferida de mobilização e de alocação de recursos, cuja primeira característica é a externalização das funções do Estado por meio da privatização e da desregulamentação das atividades sociais, econômicas e culturais; a segunda característica é a melhoria da governança por meio da qual o Estado nacional delega tarefas regulamentares e outras tarefas relacionadas à governança de escala superior; e a terceira característica diz respeito à degradação da governança a práticas e arranjos "locais" baseados numa multiplicidade de interesses.

Dessa maneira, na cidade pós-política (SWYNGEDOUW, 2007), o conflito de visões ideológicas globais é substituído por uma colaboração de tecnocratas iluminados, cujo acordo 
é alcançado sob o disfarce de um consenso mais ou menos universal que exclui os "espaços de litígio" (ŽIŽEK, 1999). A construção do consenso pós-político urbano é radicalmente reacionário, uma vez que antecipa a articulação de trajetórias divergentes, conflitantes, e alternativas para possibilidades e organizações urbanas futuras. De acordo com Rancière (1995), os conceitos vagos de cidade criativa, de cidade competitiva, de cidade inclusiva, de cidade global e sustentável servem para substituir os "nomes próprios" da democracia, espaço onde o sem nome, o não contado, e, portanto, o não simbolizado tornam-se nomeados e contados.

Deve-se advertir, por fim, que, para que as funções sociais da cidade sejam ordenadas no sentido de que ocorra o seu pleno desenvolvimento, é fundamental que essas funções se tornem conhecidas não apenas pelos formuladores e executores da política de desenvolvimento urbano, mas por todos os sujeitos afetados. Entretanto, encontrar e reconhecer essas funções, na amplitude e diversificação do ambiente urbano, não é uma tarefa fácil. Todavia, as funções da cidade aqui elencadas, se não forem ordenadas no sentido da promoção da justiça social urbana, da melhoria da qualidade de vida dos habitantes do meio urbano, proporcionando-lhes o bem-estar, não podem receber o qualificativo de sociais, porquanto serão apenas funções da cidade.

Dessa maneira, com base no romance A caverna (SARAMAGO, 2000), o artigo procurou analisar a (in) capacidade de se desenvolver uma consciência moral autônoma e a inclinação à submissão cega e passiva a formas de domínio autoritárias, uma vez que as consciências se tornaram efêmeras e frágeis em relação a um mundo de fluxos e de instabilidades. O exame criterioso da contemporaneidade reflete a respeito de uma época conturbada em que os artefatos maquínicos direcionam a subjetividade humana e transformam o seu corpo, colocando-o em questão. O universo a que nos remete o romance saramaguiano é o de um mundo mediado pela técnica do virtual e do digital que exige novas formas de percepção da realidade. Dessa maneira, criam-se novos desejos e novos espaços de atuação, pois as formas habituais de representação sofreram abalos inesperados e foram colocadas à deriva, pois representar denota dar sentido ao real que se constitui pela relação conflitante entre homens e coisas. 


\section{REFERÊNCIAS}

ADORNO, T. Dialética do esclarecimento. Rio de Janeiro: Zahar, 1995.

ALTHUSSER, L. La filosofia como arma de la revolución. Córdova, 1968.

ARANTES, O. A cidade do pensamento único. Petrópolis: Vozes, 2000.

AUGÉ, M. Não-lugares. Campinas: Papirus, 1994.

BAPTISTA-BASTOS, A. José Saramago - aproximação a um retrato. Lisboa: Publicações Dom Quixote, 1996.

BAUMAN, Z. Amor líquido. Rio de Janeiro: Zahar, 2004.

Modernidad líquida. Buenos Aires: Fondo de Cultura Económica, 2003.

BURNETT, C. F. L. Da tragédia urbana à farsa do urbanismo reformista. Tese (Doutorado em Políticas Públicas) - Faculdade de Serviço Social, Universidade Federal do Maranhão, São Luís, 2009. Disponível em: http://labhab.fau.usp.br/biblioteca/teses/ burnett_tesemestrado_tragpartic.pdf. Acesso em: 12 jan. 2017.

CANDIDO, A. Literatura e sociedade. Rio de Janeiro: Ouro sobre Azul, 2006.

CHOAY, F. O urbanismo. São Paulo: Perspectiva, 1992.

DEBORD, G. Societé du spectacle. Paris: Champs Libre, 1971.

FACINA, A. Literatura $\mathcal{E}$ sociedade. Rio de Janeiro: Zahar, 2004.

HABERMAS, J. Teoria da acción comunicativa. Madrid: Taurus, 1999.

JAMESON, F. Pós-modernismo. São Paulo: Ática, 1996.

KRITSCH, R.; SILVA, A. L. Considerações acerca da noção de razão pública no debate Rawls-Habermas. Revista de Sociologia e Política, Curitiba, v. 19, n. 39, p. 67-90, jun. 2011. Disponível em: http://www.scielo.br/pdf/rsocp/v19n39/a06v19n39.pdf. Acesso: 18 jan. 2017. 
LE CORBUSIER. Carta de Atenas. São Paulo: EdUSP/Hucitec, 1993.

LEFEBVRE, H. O direito à cidade. São Paulo: Centauro, 2001. A revolução urbana. Belo Horizonte: EdUFMG, 1999.

LOURENÇO, E. A nau de Ícaro. São Paulo: Companhia das Letras, 2001.

LOWY, M. Redenção e utopia. São Paulo: Cia. Das Letras, 1989.

LUKÁCS, G. A teoria do romance. São Paulo: Duas Cidades/ Editora 34, 2000.

MANDEL, E. O capitalismo tardio. São Paulo: Abril Cultural, 1982.

MARTINS, S. O urbanismo esse (des)conhecido saber político. Revista Brasileira de Estudos Urbanos e Regionais, Recife, n. 3, p. 39-59, out. 2000. Disponível em: http://rbeur.anpur.org.br/ rbeur/article/view/45/31. Acesso em: 20 jan. 2017.

MARX, K. O capital. São Paulo: Nova Cultural, 1996.

MAUSS, M. Essai sur le don. Paris: Editions Galilée, 2010.

RANCIÈRE, J. La Mésentente: politique et philosophie. Paris: Editions Galilée, 1995.

RAWLS, J. O liberalismo político. São Paulo: Ática, 2000.

SANTOS, B. S. Pela mão de Alice. São Paulo: Cortez, 1997.

SARAMAGO, J. A caverna. São Paulo: Companhia das Letras, 2000.

SWYNGEDOUW, E. Impossible/undesirable sustainability. New York: Guilford, 2007.

SULEIMAN, S. R. Le roman à thèse. Paris: PUF, 1983.

WATT, I. The rise of the novel. London: Chatto and Windus, 1957.

ZIZEK, S. The ticklish subject. London: Verso, 1999. 


\section{Abstract \\ Narratives of absence and power: the representation artifice in Saramago's thesis novel}

In "roman à these" A caverna, Saramago produces an representation artifice that permits to elucidate forms of dominance, whose analysis derives from the criticism of the functioning of the principle of the market that limits the State and delegitimizes forms of sociability already proposed, whether by its liberal phase or by the organized phase of late capitalism. At the same time, it reveals other sociabilities subordinated by modernity. It is emphasized how ethnical and political discourses fulfill the communicative conditions for a hermeneutic self-comprehension of collectivity, since they enable an authentic self-comprehension and lead to the criticism of a project of identity, in which it is necessary the fulfillment of certain conditions of a systematically non-deformed communication.

Keywords: Saramago; late capitalism; sociability; urbanism; post-politics. 